\title{
An integrated approach to the study of written communication in students with dysgraphia.
}

\author{
Natalia Yakovleva, \\ St. Petersburg Academy of Postgraduate Pedagogical Education Department of Special \\ (Correctional) Pedagogy, Lomonosova St., 192000, 11-13, St. Petersburg, Russia.
}

\begin{abstract}
Annotation. The article is devoted to the problem of an integrated approach to the study of written communication in fourth-grade students. The topic was not touched upon by chance, since a significant number of schoolchildren are moving to the level of basic general education with uncorrected dysgraphia, which causes difficulties in mastering not only the program in the Russian language and literature. The article presents: analytical data on the number of schoolchildren with impaired written language, methods that include not only the study of the oral and written language of schoolchildren, but also those functions that provide the written communication process. The author describes the author's methodology for examining communication, which is based on French technology, called the "Pedagogical Workshop" in Russia. The article presents some survey results.
\end{abstract}

Writing disorders are one of the problems of modern education. DI. Feldstein points out that the number of children with speech impairment in senior preschool and primary school age has doubled over 15 years (from 1997 to 2012), and up to 50\% of students go to primary school with an unformed writing skill. These data are confirmed by the annual reports of speech therapists of St. Petersburg. The number of children with speech impairments almost doubled (2007 - 7207 students, 2018 - 14987 students). Every year, teachers- speech therapists examine an average of 92776 children in the first and fourth grades, the average number of students who have some kind of speech and writing impairment is an average of $22 \%$.

Figure 1. Comparative analysis of the number of children with various writing disorders 


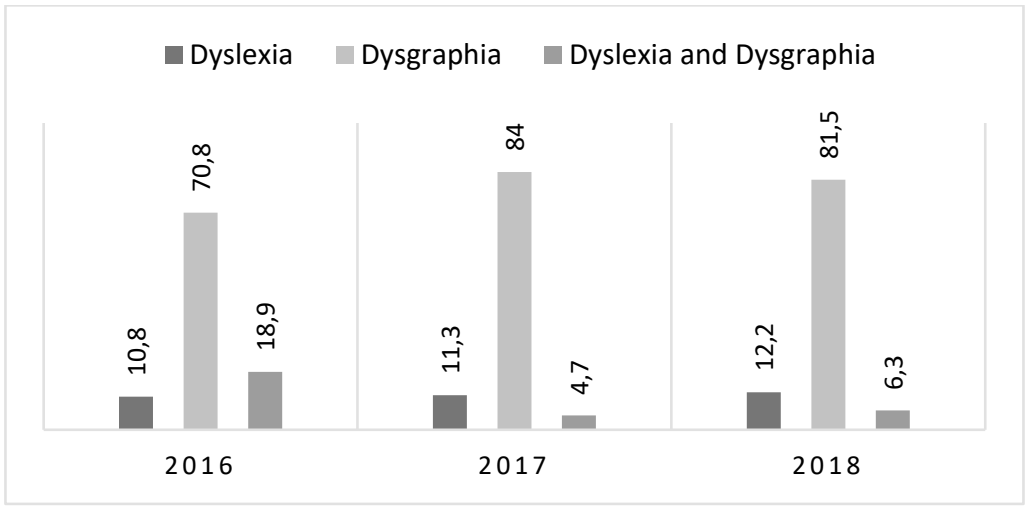

Figure 1 presents a comparative analysis of the number of children with various disorders of writing, which shows that dysgraphia is predominant, an average of $78.8 \%$ of the total number of students. I would like to draw attention to the decrease in the number of students (from 18, 9 in 2016 to $6.3 \%$ in 2018) with combined disorders (dysgraphia and dyslexia). It should be noted that the data were presented by speech therapy centers where children who have difficulties in mastering the educational program are involved. In our opinion, when applying to the psychological-medical-pedagogical commission for children, taking into account the complexity of the violation, an adapted general education program was recommended, which is implemented both in a special school or classroom, and in conditions of inclusive education.

About 62 percent of students complete correctional education annually, with a third of children leaving a speech therapy center just because they are completing elementary school.

What is the reason for the increase in children with written disorders and insufficiently effective correction of this violation? Numerous studies (T.V. Akhutina, A.N. Kornev, R.I. Lalaev, A.R. Luria, A.V. Semenovich, G.V. Chirkina, A.V. Yastrebova, etc.) point to various reasons, one of which is a deficient level of development of brain mechanisms that naturally affect the insufficiency or impairment in the development of cognitive processes, which provide full mastery of the written language by children $[3,4.5,10]$.

Modern approaches to the correction of written disorders are not only in a timely and accurate diagnosis of the causes of dysgraphia and dyslexia, which allows us to understand the specifics of the violation and the underlying psychophysiological mechanisms, but also in determining individual differences in the cognitive sphere of each student. And we are talking not only about differences in the development of the intellectual sphere, but also about the cognitive style - "individual peculiar ways of processing information inherent in a person” (M.A. Kholodnaya) [9].

From the standpoint of cognitive pedagogy, work efficiency depends on the "features of the instrumental side of the student's cognitive organization", which includes, along with external tools, "internal" (intelligence, cognitive styles, mental functions) that provide information processing and transformation. To date, this aspect in special pedagogy, and, in particular, in speech therapy is not considered enough.

An analysis of the written work of schoolchildren with dysgraphia indicates that it is currently difficult to correlate writing disabilities with the type of dysgraphia that is part of the generally accepted classification. Most often this is a combination of various types of dysgraphia according to the generally accepted classification compiled by R.I. Lalaeva, due to phonetic problems, lack of analysis and synthesis, lexico-grammatical disturbances in oral speech. We are talking about the so-called mixed or complex dysgraphia. 


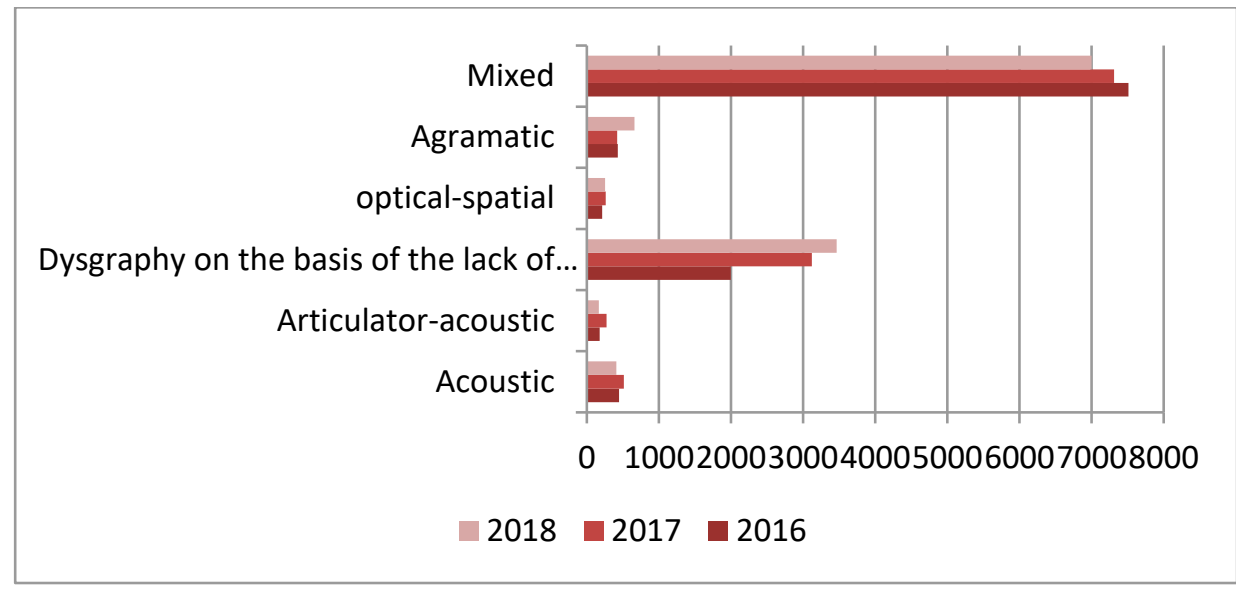

Figure 2. Distribution of identified dysgraphia in schoolchildren

Figure 2 clearly demonstrates that the largest number of children among the examined has dysgraphia due to the lack of formation of language analysis and synthesis and mixed dysgraphia. By mixed dysgraphia, we understand the violation of writing, due to the lack of development of phonetic-phonemic, lexical and grammatical components of oral speech, cognitive functions.

Our own studies show that for students with complex dysgraphia, not only dictation writing suffers, but also independent writing (presentation, composition) requiring the possession of certain operational skills.

The study of independent written works (presentation, composition) of fourth-grade students revealed a significant number of grammatical and syntactic errors. In children, both the control (with the conditional norm of speech development) and the experimental (students with dysgraphia) groups, an insufficient ability to coordinate different parts of speech, to construct sentences, to link them into a full text was noted. The monologue was reduced not to a holistic transmission of the text, but to the enumeration of individual words, unrelated sentences, serious errors were made in the use of lexical and grammatical means of speech utterance: agrammatisms, violation of the word order in a sentence. More data errors were observed in students with dysgraphia $(23 \%$ and $68 \%$ of students, respectively). Particularly difficult for children with dysgraphia is the creation of text on a given topic.

We conducted a study of the higher mental functions of memory, attention, developmental thinking with dysgraphia and written communication among elementary school students with the norm of speech and dysgraphia, and in the future to test it and analyze the results.

Recognizing that written communication is one of the types of speech activity, when developing the methodology, we relied on the psychological mechanisms of its development:

- the mechanism of comprehension, providing the informative side of speech, the structure of the organization and its language design, awareness of the motive and purpose of speech communication, planning and programming of speech activity, monitoring its course and results;

- the mechanism of mnemonic organization, which provides a meaningful aspect of speech (displaying in speech of objects and phenomena of the surrounding world, its linguistic expression (updating methods, speech, language and social standards of speech communication, rationing the design of speech utterances); 
- the mechanism of proactive analysis and speech synthesis (the mechanism of speech forecasting or speech prediction) (N.I. Zhinkin, I.A. Zimnyaya) [2].

The technique consisted of three blocks.

The first block of tasks was aimed at the study of cognitive processes (memory, attention, thinking).

To study attention, we took a Bourdon proofreading test, which allowed us to determine the stability of attention and the ability to switch attention. The methodology "Correct the mistake" proposed (P.Ya. Halperin, S.L. Kabylnitskaya) we used to determine the level of development of attention in students and their ability to recognize the semantics of the text [1].

The study of memory in schoolchildren with dysgraphia was carried out on the basis of tests by the method of memorizing two rows of words. Tests allowed to determine the type of memory, the amount of semantic and mechanical memory. To study auditory, visual and combinatorial memory, the "10 words" method was used by A.R. Luria. To study the logic and flexibility of thinking, the level of development of thinking, we used the following methods: "Exclusion of superfluous", "Study of the speed of thinking", a modified technique developed by E. F. Zambatsevichene based on the test of the structure of intelligence of R. Amthauer.

The second block of tasks was aimed at studying the oral speech of students, namely the lexical and grammatical categories and connected speech. For their study, we used a test diagnosis of speech disorders of schoolchildren using neuropsychological methods T.A. Fotekova and T.V. Akhutina. The choice of this technique is not accidental, it allows the analysis of speech deficiency at the neuropsychological level, to determine the psychological mechanisms of violation, to determine speech operations, which language relationships (syntagmatic: design, programming of the lexical and grammatical structure, integrity of the speech or paradigmatic: the choice of language units) is violated or not formed [5].

Given the numerous studies (T.V. Akhutina, A.N. Kornev, R.I. Lalaeva, A.R. Luria, A.V. Semenovich, G.V. Chirkina, etc.), indicating various causes of violation of the letter, one of which is a deficient level of development of brain mechanisms that naturally affect deficiency or impairment in the development of cognitive processes and ensure full mastery of written speech by children, we suggested that children with dysgraphia will have insufficient motivation for learning activities in general, and for speech in particular $[3,4,5,6]$. Therefore, the third block of the study was aimed at studying motivation and cognitive styles to measure intellectual behavior. We have adapted the profile of N.G. Luskanova "Study of school motivation" and the questionnaire T.I. Nezhnova, which made it possible to assess the level of development of sociability of younger students in the process of playing activity. To study cognitive styles, we used the methods proposed by M.A. Kholodnya. They made it possible to determine the characteristics of the perception of the educational task and the content of the proposed material; students' motivation for the activity and its result, the level of independence and introspection, the ability to work in a group and individually. In addition, this study made it possible to determine the teaching styles of a polydependent or polyindependent teacher, and how this feature affects the quality of education of children with speech pathology.

The fourth block included the study of written communication. For research, the children were asked to complete three tasks: write a story in a series of plot paintings, thematic presentation and composition on a free topic. For each task, performance criteria were proposed to evaluate the compositional structure of the text, its lexical and grammatical structuring, integrity, and semantics.

To complete the idea of written communication, the ability to use existing speech and life experience in independent written texts, we used an author's technique developed on 
the basis of the technology "Pedagogical Workshop [....]. The founders of this technology are French teachers. The Atelier technology (from French atelier) in Russian pedagogy was called the French pedagogical workshops. The main purpose of this technique was to determine the level of development of children's communicative skills. The theme for the study was chosen life safety. The methodology is represented by five tasks: selection of associations to the words "security", "life"; compiling a dictionary for the phrase "life safety"; classification of the dictionary on a given topic and writing a definition of the concept of "life safety". For each task, criteria were developed that made it possible to determine the level of development of the dictionary, coherent written language, and the ability to actualize life competencies in writing.

Let us present some research results.In the methodology of E.F. Zambatsevichene, to determine the level of development of thinking of younger schoolchildren, groups of tests are proposed that allow you to identify levels of awareness, ability to perform logical actions, abstract and generalize. Assessed, and the ability of children to listen and perceive instructions for the assignment.

Analysis of the results of the assignments showed that students with dysgraphia needed the maximum help of the experimenter. A particular difficulty was caused by tests that, in addition to active mental activity, required substantive knowledge ("A tree always has ... (a) leaves, b) fruits, c) buds, d) roots, e) shadow, etc.). The results of the test stated the lack of ideas, abstract thinking. Students with dysgraphia (37.2\%) had difficulty accepting the help of an experimenter, they forgot the task in the process of work, therefore, they gave inadequate answers. In $17 \%$ of the students surveyed, there was a chaotic, rash implementation of the proposed tasks and rejection of the help of the experimenter. With an obvious understanding of the instruction as a whole, there were problems with updating the word or phrase in a coherent speech, which may indicate mechanical memorization of the received ideas about the subject, the object without awareness of its semantic landmarks, instability of attention, decreased self-control, scarcity of vocabulary, which naturally affects the processes making speech utterance.

Performing the "Fifth Superfluous" subtest caused considerable difficulties for students in the experimental and control groups. In this test, frequently encountered words and words were presented, which are presented in literary works studied at school, in television programs, but are not often used in everyday life (edged weapons, torch, etc.). During the assignment, students of both groups showed a weak level of ability to save and use a given method of reasoning, a low degree of development of such mental operations as generalization, distraction and, as a result, an extremely insufficient level of practical knowledge of linguistic material.

The subtest "Paired analogies" revealed that the main problem for students in the control and experimental groups was the abstraction from the method of solving the previous problem, which indicates the inertia of mental operations. Children of the experimental group with difficulty established logical connections and relations between pairs of words, forgot the essence of the tasks. Students with dysgraphia showed a low ability to classify objects according to their characteristics, which indicates the insufficiency of such thinking operations as analysis, synthesis, abstraction, generalization.

When completing the tasks of the fourth subtest "Generalization", an insufficiently formed ability was identified to distinguish the generic characteristics of objects and phenomena in both groups, but the percentage in children with dysgraphia is much higher $(19.3 \%$ and $36,4 \%)$. Most often, children are guided by the species characteristics of objects ("dishes", "military", "rainfall").

To study the lexical and grammatical categories and connected speech, we used the diagnosis of speech disorders of schoolchildren using neuropsychological methods proposed by T.V. Akhutina and T.A. Fotekova [7]. An analysis of the results of the study 
showed the lack of development of these components in schoolchildren in both the control and experimental groups (Figure 3).

Figure 3. The formation of oral speech in primary school students

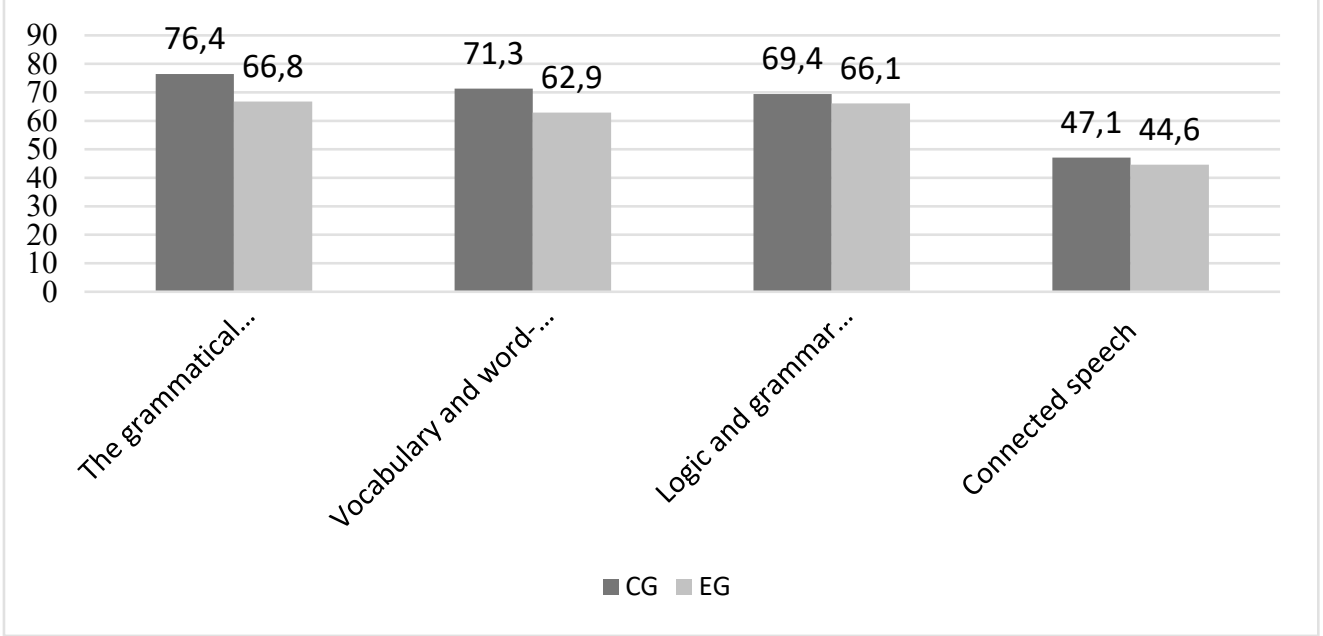

Especially difficult for both groups were tasks for verifying sentences and understanding logical and grammatical constructions, which required a high level of development of logic, attention, speech generalizations, and the ability to update the dictionary in other types of tasks. Both groups have a fairly low rate of development of coherent speech. The figure shows the correlation between the development of coherent speech and the formation of vocabulary, grammar, cognitive functions that provide the compositional structure of the text, lexical and grammatical structuring, the choice of language tools for its design.

The level of development of verbal-logical thinking in children with dysgraphia is significantly lower than their peers without pronounced speech impairment. The results of a stating experiment showed insufficient formation of conceptual thinking, inability to distinguish between concepts, children have poorly expressed or lack the skills of arbitrary control of their own activities, they have great difficulty understanding the proposed instructions, and analyze the proposed sample. There is also a very low development of basic cognitive skills. Students hardly perform tasks aimed at determining the ability to establish logical connections and relations between concepts. In addition, in 14\% of children a lack of vocabulary, a low level of cognitive activity and an interest in intellectual activity are noted. The results of the experiment indicate the underdevelopment of basic cognitive skills, such as hand-eye coordination, voluntary attention in almost all students in the experimental group. Only $32 \%$ of children with dysgraphia are characterized by stable performance, they know how to work according to the model, differentiate the essential features of objects or phenomena from non-essential, secondary, master generalization and distraction operations to a sufficient degree, can establish logical connections and relationships between concepts, save and use the set way of reasoning. The vocabulary of this group of students corresponds to the age norm. They have a good level of cognitive activity and interest in intellectual activity.

A comparative analysis of errors in independent written texts and features of the development of thinking in students with dysgraphia allows us to conclude that the ability to perform logical actions, abstract and generalize, and the ability to adequately perceive a learning task affects the choice of language and grammatical means for constructing a text. The development of the cognitive basis of writing determines the development of not only 
the surface structure of speech utterance, which is distinguished by grammatical analysis, but also its deep structure, containing semantic information.

In the future, we plan to describe in more detail the influence of motivation on the development of written communication and cognitive styles that allow us to evaluate the collectivistic capabilities of students, the ability to analyze their own activities and their results, teaching styles and their impact on the quality of life of students.

\section{Bibliography.}

1. Gal'perin P. YA., Kabyl'nitskaya S. L. Eksperimental'noye formirovaniye vnimaniya. M.: Izdatel'stvo Moskovskogo universiteta, 1974.

2. Zimnyaya I.A. Lingvo-psikhologiya rechevoy deyatel'nosti. - M.: Moskovskiy psikhologo-sotsial'nyy institut, Voronezh: NPO «MODEK», 2001.

3. Kornev A.N. Osnovy logopatologii detskogo vozrasta. Klinicheskiye i psikhologicheskiye aspekty. SPb.: Meditsina, 2006.

4. Lalayeva R.I. Narusheniye chteniya i puti korrektsii u mladshikh shkol'nikov. - SPb.: Soyuz, 1998.

5. Luriya A.R. Vysshiye korkovyye funktsii cheloveka. M.: Akademicheskiy proyekt, 2000 .

6. Semenovich A.V. Neyropsikhologicheskaya diagnostika i korrektsiya v detskom vozraste. - M.: 2002.

7. Fotekova T.A., Akhutina T.V. Diagnostika narusheniy rechi u shkol'nikov neyropsikhologicheskimi metodami: Uchebnoye posobiye dlya logopedov i psikhologov. M .: ARKTI, 2002.

8. Kholodnaya M.A. Kognitivnyye stili: o prirode individual'nogo uma. Uchebnoye posobiye - M .: PER SE, 2002.

9. Yakovleva N.N. Formirovaniye kommunikativnykh navykov uchashchikhsya $\mathrm{s}$ intellenktual'noy nedostatochnost'yu: monografiya. - SPb .: SPbAPPO, 2009. - (Nauchnyye shkoly 